University of Louisville

ThinkIR: The University of Louisville's Institutional Repository

$12-2018$

\title{
Evaluation of the predictive ability of a screening instrument used to diagnose co-occurrence of anxiety in children with high- functioning autism.
}

\author{
Austin Zachary \\ University of Louisville
}

Follow this and additional works at: https://ir.library.louisville.edu/etd

Part of the Epidemiology Commons

\section{Recommended Citation}

Zachary, Austin, "Evaluation of the predictive ability of a screening instrument used to diagnose cooccurrence of anxiety in children with high-functioning autism." (2018). Electronic Theses and Dissertations. Paper 3093.

https://doi.org/10.18297/etd/3093

This Master's Thesis is brought to you for free and open access by ThinkIR: The University of Louisville's Institutional Repository. It has been accepted for inclusion in Electronic Theses and Dissertations by an authorized administrator of ThinkIR: The University of Louisville's Institutional Repository. This title appears here courtesy of the author, who has retained all other copyrights. For more information, please contact thinkir@louisville.edu. 


\title{
EVALUATION OF THE PREDICTIVE ABILITY OF A SCREENING INSTRUMENT USED TO DIAGNOSE CO-OCCURRENCE OF ANXIETY IN CHILDREN WITH HIGH-FUNCTIONING AUTISM
}

\author{
By
}

\author{
Austin Zachary \\ B.S., Bellarmine University 2016
}

\begin{abstract}
A Thesis Submitted to the Faculty of the
Partial Fulfillment of the Requirements

for the Degree of

Master of Science

in Epidemiology

Department of Epidemiology

University of Louisville

Louisville, Kentucky
\end{abstract}

School of Public Health and Information Sciences of the University of Louisville in

December 2018 

EVALUATION OF THE PREDICTIVE ABILITY OF A SCREENING INSTRUMENT USED TO DIAGNOSE CO-OCCURRENCE OF ANXIETY IN CHILDREN WITH HIGH-FUNCTIONING AUTISM

$$
\text { By }
$$

Austin Zachary

B.S., Bellarmine University 2016

A Thesis Approved on

November 28, 2018

by the following Thesis Committee:

Stephanie D. Boone, Ph.D. - Thesis Director

Richard N. Baumgartner, Ph.D.

Doug Lorenz, Ph.D.

David W. Lohr, Ph.D.

Lonnie Sears, Ph.D. 


\section{ACKNOWLEDGEMENTS}

I would like to thank Dr. Stephanie Boone for her knowledge and endless support throughout the process. I would also like to thank Dr. Richard Baumgartner and Dr. Douglas Lorenz for their insights and assistance. I would like to express gratitude to Dr. Lonnie Sears and Dr. David Lohr for the opportunity for me to work with their data for this project. A special thanks to my family and my girlfriend, Bailey. Thank you for keeping me focused and driving me to be the best I can be. 


\section{ABSTRACT \\ EVALUATION OF THE PREDICTIVE ABILITY OF A SCREENING INSTRUMENT USED TO DIAGNOSE CO-OCCURRENCE OF ANXIETY IN CHILDREN WITH HIGH-FUNCTIONING AUTISM}

\section{Austin Zachary}

November 28, 2018

Anxiety has shown to have a high co-occurrence in children with Autism Spectrum Disorder (ASD), but has been difficult to co-diagnose. This study analyzed the ability of the Screen for Child Anxiety-Related Emotional Disorders (SCARED) to predict positive ASD screenings of the Social Responsiveness Scale (SRS). Parents and children ages 8 to 18 years $(N=100)$ were screened for anxiety using the SCARED and autism using the SRS. Moderate correlation was found between parent-reported SCARED and positive screening of the SRS $(r=.579)$, with weak correlation found in the child-reported SCARED $(r=.105)$. LASSO regression was conducted to assess SCARED predictability of the SRS. Two of forty-one questions from the parent-reported SCARED significantly predicted a positive screening of the SRS. Age was a significant predictor of this association $(O R=1.141)$. The SCARED has shown significant predictability of positive screenings on the SRS in children with autism. 
TABLE OF CONTENTS

PAGE

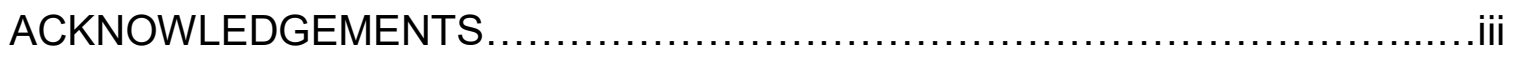

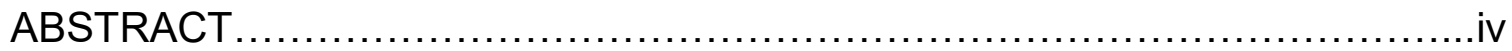

LIST OF TABLES ...................................................................

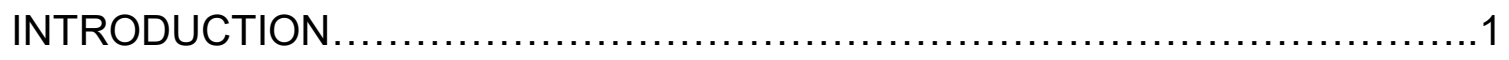

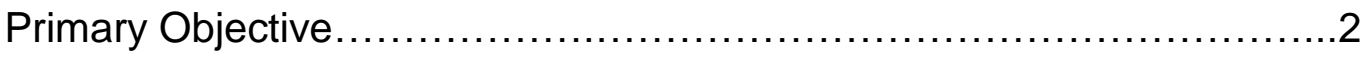

Specific Aims and Hypotheses............................................

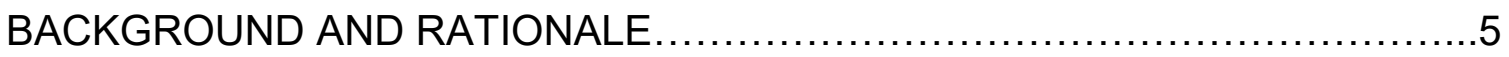

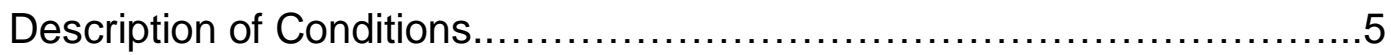

Epidemiology of ASD and Anxiety Disorder in Children in the General U.S.

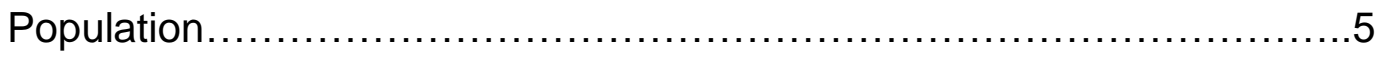

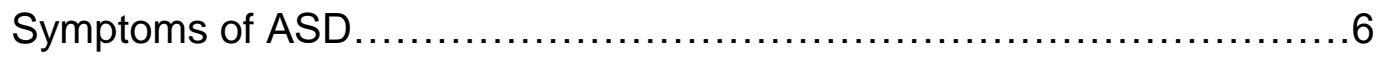

Symptoms of Anxiety Disorders ..........................................

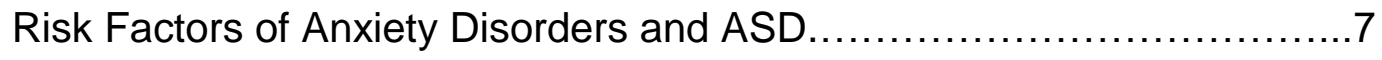

Co-occurrence of Anxiety Disorders in Children with ASD $\ldots \ldots \ldots \ldots \ldots \ldots \ldots$ 


\section{TABLE OF CONTENTS, CONTINUED}

PAGE

Previous Studies Linking Anxiety Disorders and ASD ......................

Screening Tools for Anxiety in Children with ASD........................10

Screen for Child Anxiety-Related Emotional Disorders (SCARED)........11

Previous Studies Evaluating the SCARED Instrument....................12

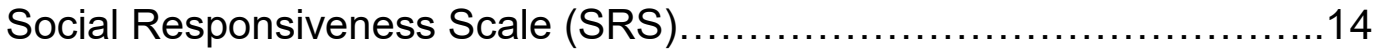

Previous Studies Evaluating the SRS ..................................14

Biological Mechanisms for Co-occurrence of ASD and Anxiety............17

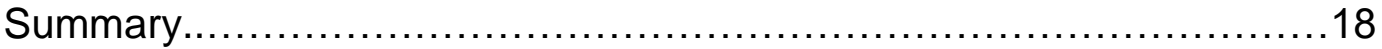

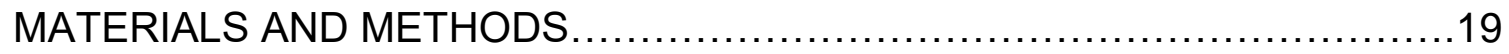

Study Population ......................................................... 19

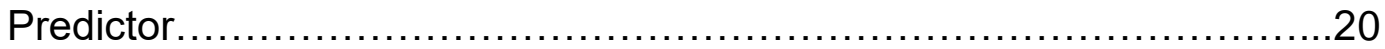

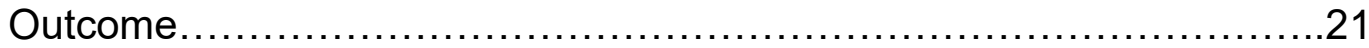

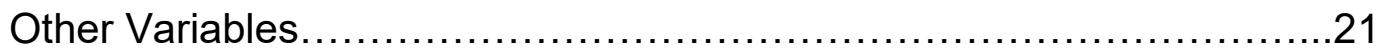

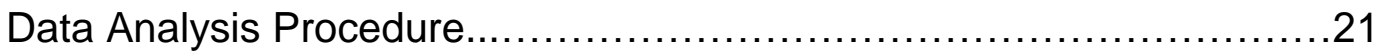

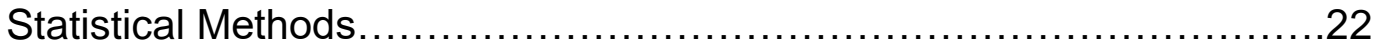

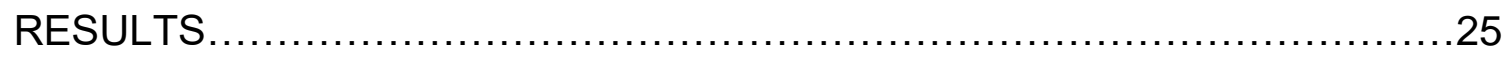




\section{TABLE OF CONTENTS, CONTINUED}

PAGE

Descriptive Results.

Correlation Between the Parent- and Child-reported SCARED and the

SRS

Predictive Ability of the SCARED on Positive Screening of the SRS via LASSO Regression.

Associations Between the Child- and Parent-reported SCARED and SRS when Stratified by Demographics.

DISCUSSION.

Strengths and Limitations.

Conclusion

REFERENCES 


\section{LIST OF TABLES}

TABLE

PAGE

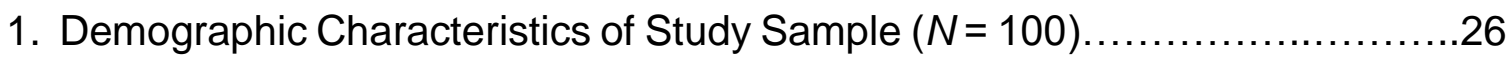

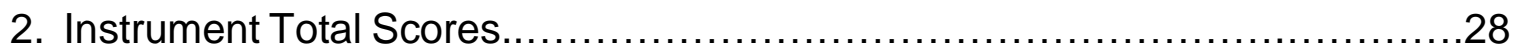

3. Largest Lambda Values via the LASSO .........................................33

4. Assessment of Variables of Screening Positive on SRS ........................34

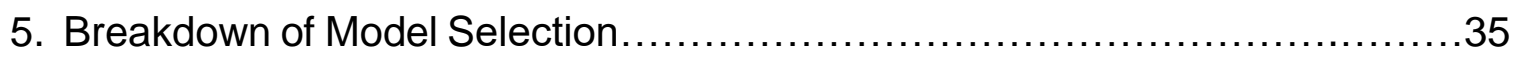

6. Most Parsimonious Model for Assessment of Demographics....................36 


\section{INTRODUCTION}

Anxiety and Autism Spectrum Disorder (ASD) are among the most diagnosed mental conditions in children, with a common co-occurrence of both disorders (1). While it is known that both co-occur frequently, previous manuals used by physicians to diagnose mental conditions have recommended against co-diagnosis (2). This previous thought comes from the repetitiveness of symptoms shown in children with either ASD or anxiety, along with the difficulty of children with ASD to properly report on one's emotions (3). Although this thinking has evolved, there is no gold standard by which co-occurrence of both disorders may be diagnosed in a patient. The formulation of a method of accurately predicting anxiety in a population of children with autism will allow for more effective treatment of both disorders.

The Screen for Child Anxiety-Related Emotional Disorders (SCARED) is a parent- and child-reported instrument that evaluates anxiety in children. The Social Responsiveness Scale (SRS) is a parent reported instrument that evaluates their children for symptoms of ASD. Both the SCARED and SRS have been used in research, but there have been gaps in the research. Although previous studies have compared different anxiety measures to the SRS, however the SCARED has not been critically evaluated for its predictive ability of the SRS. 
This study was conducted to evaluate associations between a scale used to diagnose anxiety disorders (SCARED) and a scale used to diagnose ASD (SRS) in children between the ages 8-18 years diagnosed with ASD.

\section{Primary Objective:}

To determine if the SCARED is an accurate predictor of a positive or severe screening on the SRS in children aged 8 to 18 years of age diagnosed with ASD.

\section{Specific Aims:}

Study Aim 1:

a) To determine the correlation between the parent-reported report of anxiety disorders (SCARED) and severity of ASD (SRS) in children with ASD.

b) To determine the correlation between the child-reported report of anxiety disorders (SCARED) and severity of ASD (SRS) in children with ASD.

\section{Hypothesis 1:}

Both the parent and child-reported report of the SCARED will have a positive correlation with the SRS, with the parent-reported versions having a stronger correlation. 
Study Aim 2:

a) To evaluate the ability of the parent-reported version of the SCARED to accurately predict a positive screening of the SRS in children with ASD.

b) To evaluate the ability of the child-reported version of the SCARED to accurately predict a positive screening of the SRS in children with ASD.

\section{Hypothesis 2:}

Both the parent-reported and child-reported versions of the SCARED will significantly predict the SRS.

Study Aim 3:

a) To evaluate the association between the parent-reported version of anxiety disorders (SCARED) and the ASD (SRS) adjusting for age, sex, and race in children with ASD.

b) To evaluate the association between the child-reported version of anxiety disorders (SCARED) and the ASD (SRS) adjusting for age, sex, and race in children with ASD. 


\section{Hypothesis 3:}

Age will be have a significant predictability of the association between the SCARED and SRS. Both race and sex will not have significant predictability of the association between the SCARED and SRS. 


\section{BACKGROUND AND RATIONALE}

\section{Description of Conditions}

ASD is diagnosed using criteria laid out in the 5th edition of the Diagnostic and Statistical Manual of Mental Disorders (DSM-5(4)). This diagnosis is characterized by constant impairments in social communications and interactions, along with intellectual and language impairments.

Anxiety disorders are also diagnosed using the criteria laid out by the DSM-5 (4). This diagnosis includes the presence of excessive anxiety and worry about a variety of topics often for at least 6 months and causes the patient to have noticeable psychical or cognitive symptoms, such as edginess, tiring easily, and irritability.

\section{Epidemiology of ASD and Anxiety Disorders in Children in the General U.S.}

\section{Population}

According to the Center for Disease Control and Prevention, the prevalence of ASD in children who are 8 years old is approximately 1 in 68 (5). With approximately 74.2 million children living in the United States (6), approximately 1.09 million children have been diagnosed with ASD. The estimated prevalence is significantly higher in boys $(23.6$ in 1,000$)$ than 
girls $(5.3$ in 1,000). Non-Hispanic White children have the highest prevalence (15.5 per 1,000), followed by non-Hispanic Black children (13.2 per 1,000), and finally Hispanic children (10.1 per 1,000; (5)). According to the National Institute of Mental Health, approximately $31.9 \%$ of children ages 13 to 18 years old are diagnosed with anxiety disorders (7). With approximately 74.2 million children living in the United States (6), approximately 23.67 million children have been diagnosed with anxiety disorders. Females have a higher prevalence of all anxiety disorders when compared to males (7).

\section{Symptoms of ASD}

According to the DSM-5, ASD can be diagnosed with a variety of criteria, including: deficits in social communication and interaction, restricted and repetitive patterns of behavior, present in early development, clinically significant impairment in social or occupational areas, and is not better explained by an intellectual disability (4). According to the CDC, other symptoms include avoiding eye contact, avoiding physical contact, obsessive tendencies, and having delayed speech and language (8).

\section{Symptoms of Anxiety Disorders}

According to the DSM-5, anxiety disorders can be diagnosed with a variety of criteria, including: restlessness, being easily fatigued, difficulty concentrating, irritability, muscle tension, chronic worrying, and sleep problems

(4). Anxiety also causes children to be afraid when away from parents, extreme fear of specific things or situations, being afraid of social situations, including 
school, and repeated episodes of sudden and intense fear that can come with symptoms such as increased heart rate, having trouble breathing, or feeling dizzy and shaky.

\section{Risk Factors of Anxiety Disorders and ASD}

While there is no all-inclusive hypothesis on what risk factors are associated with anxiety, there are many that are suggested to be a possible cause of anxiety disorders. Possible risk factors include substance abuse, childhood traumas, stresses of everyday life, a family history of anxiety disorders, and pre-existing medical conditions, including heart disease, diabetes, and asthma. Most of these, however, pertain to anxiety in adults.

While there is no all-inclusive hypothesis on the causes of ASD, there are many factors that have been suggested as causes to multiple types of ASD. Most experts agree that genes are one of the risk factors that makes a person more likely to develop ASD (9), along with certain genetic or chromosomal conditions, such as fragile $X$ syndrome $(10-13)$ or tuberous sclerosis $(10,11,13)$. Children who are born to older parents are also at a greater risk of developing ASD (14), along with children who have siblings with ASD (15-20). Other known risk factors that are associated with ASD include: taking valproic acid and thalidomide during pregnancy $(21,22)$, multiple births, fetal distress, low birth weight, feeding difficulties, umbilical-cord complications, and hyperbilirubinemia (23). Children of foreign-born Black, Filipino, and Vietnamese mothers have higher risks of developing ASD when compared to White US-born children (24). 
There are several potential, but inconsistent risk factors for developing anxiety in children diagnosed with ASD. Risk factors such as age (25-27), sex (27-31), subtype of ASD, and IQ score (verbal and non-verbal) have been suggested, but studies have shown conflicting results for each (32). Looking into these different risk factors as a possible cause for increased anxiety would lead to better and more accurate treatments.

\section{Co-occurrence of Anxiety Disorders in Children with ASD}

Anxiety disorders have been shown to be the leading source of additional symptoms in ASD with estimates of comorbid anxiety symptoms as high as $84 \%$ (1), and 2.6 times more common than in children without ASD (7). Patients with ASD and comorbid anxiety have an increased risk at having behavior disorders compared to patients with ASD alone (25), difficulties establishing relationships with friends and family, difficulty sleeping, disrupting family functioning $(33,34)$, and social avoidance (35) when compared to youth with ASD alone. Youths experiencing both ASD and anxiety have a reported increased disruptive behavior in class, noncompliance with teacher's demands and disinterest in peers and peer-centered activities (36-39). Adolescents with ASD have been found to suffer from anxiety disorders at a higher rate when compared to externalizing disorders such as Attention Deficit/ Hyperactivity Disorder (ADHD; (40))

A meta-analysis evaluating 31 studies examining co-occurrence of conditions suggested that $39.6 \%$ of children with ASD had at least one Diagnostic and Statistical Manual of Mental Disorders-Fourth Edition (DSM-IV) 
anxiety disorder, and found that children with ASD have higher anxiety levels when compared to typically developing children (41). Mean age was found to be a significant moderator for anxiety for rates of several anxiety disorders, including generalized anxiety disorder (GAD; $Z=11.94, p<.001)$ and separation anxiety disorder $(Z=6.807, p<.001)$. Studies that had a higher mean age was found to report higher prevalence rate of anxiety in general and GAD. IQ was also found a significant moderating effect for rates of anxiety disorders such as separation anxiety disorder $(Z=5.873, p<.001)$. A longitudinal study found that a higher number of anxiety symptoms increases the risk of social communication impairment over time in children with ASD $(\beta=.22, p=.008$ : (42)).

Misclassification of co-occurring ASD and anxiety is plausible, as many of symptoms of ASD (such as repetitive behaviors, communication deficits) are shared with anxiety disorders (43). There is currently no established method to reliably diagnose anxiety in children with ASD. Psychiatric diagnostic interviews have not been established as a reliable tool. The diagnosis of ASD from the DSM-IV does not measured traditional anxiety levels, which could lead to a missed diagnosis of anxiety from mislabeling anxiety symptoms as only ASD symptoms. There is a lack of distinction of symptomology resulting in opportunities to evaluate screening instruments for the co-diagnosis of these disorders, leading to better treatment options for patients.

\section{Previous Studies Linking Anxiety Disorders and ASD}

White et al. published a meta-analysis on anxiety in children with ASD (1). With a total of 38 studies being reviewed, the proportion of children with ASD 
experiencing with some degree of anxiety ranged from $11 \%$ to $84 \%$. DeBruin et al. (44) and Siminoff et al. (45) both looked specifically at the diagnosis of mental anxiety disorders in children with ASD, finding $55 \%$ and $42 \%$ of criteria met for anxiety disorders respectively.

Joshi et al. assessed the difference of diagnosis of anxiety in children with ASD compared to those not diagnosed with ASD (46). With a total sample size of $N=2,323(n=217$ diagnosed with ASD) a significant difference in the diagnosis of multiple anxiety disorders (ASD $=61 \%$, non-ASD $=42 \%, p<.001$ ) and GAD (ASD $=35 \%$, non-ASD $=30 \%, p<.001)$ was observed between the study groups. However, there was no significant difference observed between separation anxiety disorder $(\mathrm{ASD}=37 \%$, non-ASD $=35 \%, p=.84$ ) and panic disorder $(\mathrm{ASD}=6 \%$, non-ASD $=8 \%, p=.35)$.

\section{Screening Tools for Anxiety in Children with ASD}

Kaat and Lecavalier in 2015 studied the reliability and validity between parent and child rated anxiety measures in children with ASD (47). The researchers used the Autism Diagnostic Observation Schedule-Second Edition (ADOS-2) to assess for specific social behaviors (48). The Wechsler Intelligence Scales for Children-Fourth Edition (WISC-IV) was used as a standardized measure of intelligence of children ages 6 to 16 (49). The Revised Children's Anxiety and Depression Scale (RCADS) (50) and the Multidimensional Anxiety Scale for Children (MASC-2) (51) were both completed by the children and parents to measure anxiety disorders. With a population of 46 children with parents between the ages of 8 and 16 years (mean 12.4, SD:2.3 years), Kaat 
and Lecavalier found that the reliability for the RCADS and MASC-2 were .82 ( $p$ $<.001)$ and $.83(p<.001)$, respectively.

There is no clinical assessment tool that is agreed upon to be the gold standard in accessing anxiety in ASD patients, leaving a gap in the literature (52). Previous studies have examined the predictive ability of the parent- and child-reported versions of the SCARED compared to other autism screening tools such as the ASEBA scales, the Child Behavior Checklist (CBCL), and the Youth Self-Report (YSR; (53)). However, no studies have evaluated the correlation and association between the SCARED and SRS scales.

\section{Screen for Child Anxiety-Related Emotional Disorders (SCARED)}

The Screen for Child Anxiety-Related Emotional Disorders (SCARED) is used to screen for anxiety in youth (54). The SCARED is a 41-item parent and child-report scale that screens for anxiety in youth, and shows good internal reliability and convergent validity with clinical structured interviews in children with ASD (55). Both versions of the SCARED are broken down into 5 subscales, which includes: Panic Disorder or Significant Somatic Symptoms ("When I get frightened, I feel like passing out" -child, "When my child feels frightened, it is hard for him/her to breathe" -parent), GAD ("I worry about being as good as other kids" -child, "My child is a worrier" -parent), Separation Anxiety SOC ("I have nightmares about something bad happening to me" -child, "My child is afraid to be alone in the house" -parent), Social Anxiety Disorder ("I feel nervous with people I don't know well" -child, "It is hard for my child to talk with people he/she doesn't know well" -parent), and Significant School Avoidance ("I am scared to 
go to school" -child, "My child gets stomachaches at school" - parent). The SCARED uses a 3-point Likert-scale, translating to a total score range of 0 to 82 . A total score of 25 or higher on the SCARED indicates the presence of an anxiety disorder in a child, with scores higher than 30 being more specific. Parents generally report more anxiety than children using this scale, with a mild correlation shown (56).

\section{Previous Studies Evaluating the SCARED Instrument}

Wigham and McConachie also investigated the structure and reliability of the SCARED instrument (57). A total 63 different articles were included, with a total of eight measurement tools for diagnosing ASD concluded that the SCARED instrument has good internal reliability $(\alpha=.93)$ with evidence of testretest reliability for both total scores and subscores $(\alpha=.86 ;(58))$ between the two scales. A moderate correlation between the parent- and child- reported scales $(r=.20$ to $r=.47, p<.001)$, with a correlation of $r=.33(p<.001)$ in children with ASD was reported. The SCARED has also been shown to be a valid measure of anxiety in children with autism by being cross-validated with the Achenbach System of Empirically Based Assessment Scales (ASEBA; (53)). The association of demographic variables (race, age, sex) to the child-reported SCARED score has also been studied, with only the sex of the participant being significant $(\beta=12.2, \mathrm{SE}=4.5, p=0.008$; (53)). This beta suggests that the childreported SCARED score is 12 points higher if the child is female compared to male. 
DeSousa et al., examined the sensitivity and the specificity of the SCARED instrument in a population of 119 students aged $9-18$ years $($ mean $=$ $12.66, S D=2.32)(59)$. Forty-four participants $(37 \%)$ had at least one anxiety disorder, with 26 having GAD (21.8\%), 24 having social phobia (20.2\%), and 9 having separation anxiety disorder (7.6\%). Results showed that the SCARED had a sensitivity of $81.8 \%$ and a specificity of $52.0 \%$ regarding any anxiety disorder. These results suggest that the SCARED is a useful instrument for the screening of anxiety disorders, both in general and for specific anxiety disorders.

Reaven et al., studied the SCARED and its ability to reliably measure ASD in children with at least one anxiety disorder (60). Following 50 children with ASD and anxiety disorder in a cognitive behavior therapy (CBT) for a 12-week period, Reaven found that scores on the SCARED were reduced by $34 \%$ in the CBT groups. This result was significantly better than the $6 \%$ reduction in the control group, supporting that the SCARED is an outcome measure to children with ASD. Given the small sample size of this study, additional studies need to be made to have full confidence in these results.

Stern et al., also looked at the psychometric characteristics of the SCARED in children with ASD seeking treatment for anxiety disorders (56). Results showed that the SCARED has good internal consistency for both the parent and child reports of the survey, with a Cronbach's alpha of .90 on the parent report and a .92 for the child report. The parent report on the GAD subscale was significantly higher $($ mean $=11.78, S D=3.95)$ than the children report $(($ mean $=9.93, S D=3.91), F(1,114)=5.54, p=.020)$. Parents also had a 
total higher score on the SCARED (mean $=36.42, S D=14.87$ ) than the children $(($ mean $=31.11, S D=11.61), F(1,104)=3.98, p=.049)$. From these findings, Stern et al. suggest that the SCARED "is a valid and clinically useful tool for assessing anxiety in treatment-seeking children and adolescents with ASD" ((56); page 7).

\section{Social Responsiveness Scale (SRS)}

The Social Responsiveness Scale (SRS) is used to measure social and autistic behavior in 4 to 18 year-olds (61). The SRS is a 65 -item parent/teacher questionnaire that can be completed in 15-20 minutes. The SRS can be broken into 5 subcategories, which include: Social Awareness ("Is aware of what others are thinking or feeling"), Social Cognition ("Takes things too literally and doesn't get the real meaning of a conversation"), Social Communication ("Is able to communicate his or her feelings to others"), Social Motivation ("Seems selfconfident when interacting with others"), and Autistic Mannerisms ("Behaves in ways that seem strange or bizarre"). The SRS uses a 4-point Likert-scale and

has a total range of scores from 0 to 195 . Total raw scores can be transformed into $T$ scores with a higher score indicating a higher tendency for the child to exhibit autistic behaviors in a social setting.

\section{Previous Studies Evaluating the SRS}

Duvekot et al., studied the sensitivity and specificity of the SRS in a population of 596 children aged 4-10 years (62). Devekot implemented a twophase design (63), which oversampled children who screened positive on the 
SRS in an ASD-specific diagnosis. A total of 4,344 children were sent the SRS, with a total of 1,182 completed reports returned. Of the total 596 children, 393 screened positive (total score of $\geq 75$ on the parent report), and 203 children who were randomly selected from the 789 children who screened negative. With the cutoff of 75 , the SRS resulted in a sensitivity of .85 and specificity of .83 , suggesting that the SRS is good at predicting children with autistic behaviors.

Cholemkery et al., looked at the validity of the SRS, and its ability to differentiate between ASD and other disruptive behavior disorders in 165 children aged 6-18 years (64). Cholemkery et al., recruited a total of 55 individuals with ASD, 55 individuals with oppositional defiant disorder (ODD) and conduct disorder (CD), and 55 individuals with typical development (TD) as controls. The highest results on the SRS was found in individuals with ASD (mean =97.0, SD $=26.7)$, followed by ODD/CD (mean $=59.1, S D=12.9)$, with the TD group scoring the lowest $($ mean $=19.4, S D=12.9)$. The group differences on the SRS was statistically significant $(\mathrm{F} / \mathrm{X} 2=42.22, \mathrm{df}=2, p<.0001)$.

Azad et al., examined the concordance of parents and teachers completion of the SRS for children with ASD (65). A total of 123 parents and teachers took the SRS at the beginning and the end of each school year for two school years for the appropriate child. The parents and teachers had a significant agreement on SRS total scores at the beginning $(r=.28, p=.005)$ and end $(r=$ $.47, p<.0001)$ of each school year. At the beginning of the school year, there was a statistically significant correlation between parents and teachers in each of the SRS subscales, with an exception to autistic mannerisms $(r=.16, p=.13)$. At 
the end of the school year, there was a statistically significant agreement between parents and teachers in each of the SRS subscales. For less severely ASD affected children, there was no statistically significant correlation in SRS scores at either the beginning $(r=.14, p=.48)$ or end $(r=.14, p=.46)$ of the school year.

Aldridge et al., evaluated the ability for the SRS to accurately predict a diagnostic outcome of ASD to a tertiary level (66). ASD was defined using the Diagnostic and Statistical Manual of Mental Disorders-Fourth Edition, Text Revision (DSM-IV-TR) (67), and information gathered from background reports of previous cognitive assessments and/or current academic functioning. Forty-eight children ages 4 to 15 years (mean $=8.83, S D=2.58$ ) were given the SRS before being accessed for ASD. Results show that the SRS had a high sensitivity ( $91 \%$ parent report, $84 \%$ teacher report), but had a considerably lower specificity ( $8 \%$ parent report, $41 \%$ teacher report).

Murray et al., also examined the SRS's ability to predict autism in children (68). Murray et al., looked at a population of 29 adolescents of $12-17$ years (mean $=14.5, S D=1.5)$ who are suspected of having ASD, by giving them both the SRS and Autism Diagnostic Interview-Revised (ADI-R; (69)). Of these 29 adolescents, 25 had an SRS score at or above the cutoff point of 75 , with 4 having an SRS score lower than the cutoff point. With $86.2 \%$ of the population scoring at or above the cutoff point of 75 , the SRS has been shown to be a good predictor of ASD in adolescents. 


\section{Biological Mechanisms for the Co-occurrence of ASD and Anxiety}

Previous studies have shown that the amygdala is smaller in patients with both autism and anxiety when compared to those with autism alone (70). The amygdala is the primary part of the brain with the role of perception, encoding, and retrieval of emotional information, and has been widely implicated in ASD (71), and is hypothesized to have a decreased volume in ASD patients suffering from anxiety due to excitotoxicity. The increased activity can lead to degradation of the cellular architecture and cell death of that section of the brain. Black mon et al. hypothesized that increased usage of the amygdala due to anxiety caused degradation of gray matter (72). Herrington et al. found that the right amygdala from a sample of adolescents with both autism and anxiety had a significantly decreased volume when compared to adolescents with ASD alone $(p=.04)$, while finding that the total brain volume is not significantly different $(p=$ $.08 ;(70))$.

Another explanation that has been proposed from previous studies is that abnormalities of serotonin 5-hydroxyindoleacetic acid (5-HT) can represent a causal link in autism and anxiety (30). Studies have shown that the developmental process of serotonin synthesis in the brain is disrupted in children with ASD between the ages of 2 and 15 years, causing impulsive symptoms, repetitive movements, and social features (73-75). Decreased levels of serotonin has also been shown to increase the risk of anxiety (76). 
Another possible explanation that have been suggested is the difficulty children with autism and anxiety have in processing diverse sources of information, causing these children to experience these everyday interactions as chaotic and freighting (77).

\section{Summary}

A review of the literature has shown a difficulty in traditional face-to-face diagnosis of co-occurring ASD and anxiety in adolescents. While the literature has begun to look at the predictability of instruments measuring anxiety in children with ASD, there is no gold standard of co-diagnosis. Previous studies have shown a predictive ability of the SCARED with ASD diagnostic instruments such as the ASEBA (53). However, there has not been a study that has looked at the correlations between both versions of the SCARED and the SRS, nor has there been a study that has looked at these different demographic variables and their effect on the association between the SCARED and SRS, leaving a gap in the literature. 


\section{MATERIALS AND METHODS}

\section{Study Population}

This study was conducted using data collected from Lohr et al. and methods have been previously described (53). In brief, the Bingham Clinic is a general child psychiatry clinic with referrals from providers, families, and inpatient units. The Weisskopf Child Evaluation Center provides diagnostic evaluations for children with possible developmental disabilities, genetic disorders, autism, ADHD, and other learning disabilities. The University of Louisville Autism Center provides diagnostic evaluations of autism, conducts clinical research of ASD, and provides training for caregivers and educators working with these children. To recruit participants, referrals were obtained from posted notices to the Bingham Clinic, the Weisskopf Child Evaluation Center, and the University of Louisville Autism Center, along with treating clinicians in clinics. Participants and their parents completed demographics and questionnaires during their next clinic visit or at a scheduled appointment. It took both participants and their parents about an hour to complete the questionnaires. Cases were ascertained from July 2013 through December 2014. Inclusion criteria include adolescents aged 8 to 18 years who have an established clinical diagnosis of high-functioning autism to 
limit possible response bias and were able to read and complete the questionnaires without any assistance. Missing data was addressed through contacting family members to fill in missing question items.

A total of 100 patients were recruited, 88 males and 12 females, aged 818 years (mean $=12.9$ years, $S D=2.8$ years). Eighty-eight of the subjects selfidentified as Caucasian. Sixty-four of the subjects were diagnosed with ASD with a psychological test including the use of the Autism Diagnostic Observation Schedule (ADOS). The other thirty-six subjects were diagnosed with ASD by trained clinical professionals according to the DSM-IV and DSM- 5 criteria. Eighty seven percent of the subjects had at least one comorbid psychiatric disorder, with anxiety disorder being the most common $(n=70)$. All comorbid diagnoses of the study population were obtained from the subject's medical records. All participants and their families completed informed consent as approved by the University of Louisville IRB.

\section{Predictor}

The SCARED was used to screen for anxiety in youth. The SCARED has a total range of scores ranging from 0 to 82 , with scores higher than or equal to 25 reflecting a more specific screen for at least one anxiety disorder, as per suggested by Birmaher et al. (58). Individual questions will be entered as a continuous variable, with responses of $0=$ "never true", $1=$ "sometimes true" and 2 = often true". 


\section{Outcome}

The SRS was used to screen for autistic tendencies in adolescents. The SRS has a total range of scores ranging from 0 to 195 . The total score will be converted into a dichotomous variable, severe range of diagnosis of ASD and mild to moderate range of diagnosis of ASD. For the purposes of this study, a screening in the severe range of diagnosis $(\geq 87)$ will be considered a positive screening, and a screening in the mild to moderate range $(\leq 86)$ will be considered a negative screening. These cut offs will be based on recommendations given by Constantino et al. (61).

\section{Other Variables}

Race was converted into a dichotomous variable of White and non-White. Age was self-reported and was collected at the completion of the questionnaires for Lohr et al. (53). Age group was broken into 8-10 years, 11-13 years, and 1418 years to reflect the break between school levels (elementary, middle, and high school) in the public and private schools of Jefferson County. Sex was selfreported as either being male or female.

\section{Data Analysis Procedure}

We started with a raw data set of $N=100$ with demographics and multiple self-reporting surveys. This raw data set was reduced to only include only the age, sex, race, total SRS score, total SCARED parent, and child score, and both

the parent and child responses to the SCARED. This data set was further broken into two separate data sets that either included the parent or the child responses 
to the SCARED, along with the corresponding total SCARED scores. For each of these separate datasets, participants were deleted for having missing data in any response options of the SCARED. A total $n=6$ was deleted from the parent sample, leaving $N=94$, and a total $n=11$ was deleted from the child sample, leaving $N=89$.

\section{Statistical Methods}

Statistical analysis was performed using R v. 3.4.2. The correlation between both total scores of the parent- and child-version of the SCARED compared to a positive screening on the SRS was assessed using the pointbiserial correlation method (78). The parent-reported SCARED and childreported SCARED was assessed using the Pearson correlation method (79). These methods gives an $r$ statistic, which explains the total correlation between the two variables, ranging from -1 to 1 . These associations were measured as 0

to 0.3 as a weak association, 0.3 to 0.7 as a moderate association, and 0.7 to 1.0 as a strong association (80).

The analysis of the ability of the SCARED to accurately predict scores of the SRS was completed using penalized logistic regression, utilizing the Least Absolute Shrinkage and Selection Operator (LASSO) regression (81). LASSO regression is a method used in conjunction with logistic regression, and the LASSO takes the sum of the absolute values of the coefficients found using logistic regression to be less than a fixed value, forcing some variables to approach zero, effectively removing these variables from the model. This method can make the resulting model simpler and easier to interpret. This penalty 
regression model has been shown to be an effective device for models where the number of predictors is similar to or exceeds the number of observations ( 81 , 82). The LASSO regression model gives a greater prediction accuracy along with a lower bias in the model when compared to traditional regression methods in models with a large number of variables.

The initial cross-validation model of the LASSO regression will find the optimal tuning parameter $(\lambda)$ of the model. The cross-validation model will select the tuning parameter using the mean-squared error to predict the maximum value for the sum of coefficients. The tuning parameter chosen was the lambda value that is the most regularized within one standard deviation of the minimum error as determined by the model. The selected tuning parameter gave best fit of the model by setting a limit to the level of shrinkage in the model. This selected tuning parameter was used in a second model that will select the optimal subset of variables for predicted a positive screening of the SRS. The data was also standardized to address differently scaled predictors, and to ensure the proper $\lambda$ will be calculated from the model.

With the resulting model from the LASSO regression, a logistic regression model was made using the items in the SCARED that were identified as significant in predicting the SRS. The lambda value that produced the most regularized model within one standard deviation of the lambda value that produced the minimum mean-squared error will be used, as per the suggestions by Krstajic et al. (83). An odds ratio (OR) and 95\% Confidence Intervals (Cl) was 
produced for each item, explaining whether the odds of a positive screening of the SRS occurred given the score from a selected item from the SCARED.

To evaluate the effects of a child's age group, sex, and race on the association of both the parent- and child- versions of the SCARED and the SRS, unconditional logistic regression was used. Each potential confounder was taken out of each model to find the most parsimonious model that gave the closest result to the crude model. This was achieved by selecting the model that reflected the most similar ORs when compared to the crude model. An OR and 95\% Cls was produced for each demographic, explaining the odds that a positive screening of the SRS will occur given the specific demographic characteristic. The referent group for race was White, for sex was male, and age-group was entered as a continuous variable (8-10 years, 11-13 years, 14-18 years). 


\section{RESULTS}

\section{Descriptive Results}

Majority of the sample was male (88\%), between 11 to 13 years of age (44\%) with $88 \%$ percent White (Table 1). A majority suffered from two (34\%) or three (28\%) different psychiatric disorders, with anxiety disorder (70\%) and ADHD (66\%) being the most common.

A majority of the population had a positive screening on the SRS, which indicates a severe range of diagnosis for ASD. The age group with the highest positive screening were those ages $14-18$ years (80.8\%) A higher proportion of males had a positive screening compared to females (75\% vs. $66.7 \%)$, as well as those who self-reported White race compared to non-White race (75\% vs. $60 \%)$. Positive screening data was not available for these analyses including comorbid diagnosis and type of psychiatric disorder. 
Table 1: Demographic Characteristics of Study Sample $(N=100)$

\begin{tabular}{|c|c|c|}
\hline Variables & Frequency & $\begin{array}{l}\text { Positive SRS } \\
\text { Screening (\%) }\end{array}$ \\
\hline \multicolumn{3}{|l|}{ Age Group (years) } \\
\hline $8-10$ & 30 & $20(66.7)$ \\
\hline $11-13$ & 44 & $33(75.0)$ \\
\hline $14-18$ & 26 & $21(80.8)$ \\
\hline \multicolumn{3}{|l|}{ Gender } \\
\hline Male & 88 & $66(75.0)$ \\
\hline Female & 12 & $8(66.7)$ \\
\hline \multicolumn{3}{|l|}{ Race } \\
\hline White & 88 & $66(75.0)$ \\
\hline Non-White & 10 & $6(60.0)$ \\
\hline \multicolumn{3}{|l|}{ Comorbid diagnosis ${ }^{a}$} \\
\hline Zero & 13 & - \\
\hline One & 22 & - \\
\hline Two & 34 & - \\
\hline Three or More & 31 & - \\
\hline \multicolumn{3}{|l|}{$\begin{array}{l}\text { Type of psychiatric } \\
\text { disorder }\end{array}$} \\
\hline GAD & 70 & - \\
\hline ADHD & 66 & - \\
\hline OCD & 15 & - \\
\hline Major depression & 12 & - \\
\hline $\begin{array}{l}\text { Impulsive control disorder } \\
\text { NOS }\end{array}$ & 8 & - \\
\hline Mood disorder NOS & 6 & - \\
\hline PTSD & 5 & - \\
\hline $\begin{array}{l}\text { Oppositional defiant } \\
\text { disorder }\end{array}$ & 4 & - \\
\hline
\end{tabular}


The average total score on the SRS was 110.48 (SD \pm 29.20 ; range 53 176) (Table 2). A total of 74 participants had a severe range of ASD diagnosis with total scores greater than or equal to 87 , as per suggested by Constantino et al. (61). The highest average total score on the subscales was for Social Communication (37.28, SD \pm 10.94 ), followed by Autistic Mannerisms (21.87, SD $\pm 7.14)$ and Social Cognition $(20.73, S D \pm 6.47)$. Social Communication has the highest subscore due to the fact that it has the most questions in the instrument, and did not have the highest average score per question (1.69) between each subscale.

The average total of the child-reported SCARED was 27.06 (SD \pm 15.88 ; range 2 - 63) (Table 2). A total of 52 participants had significant total score with greater than or equal to 25 , as per suggested by Birmaher et al. (54). The highest average total score on the subscales was for $\operatorname{GAD}(7.08, \mathrm{SD} \pm 0.57)$, followed by Panic Disorder (6.47, SD \pm 0.54$)$ and Social Anxiety Disorder (6.40, SD \pm 0.52 ). GAD was the highest subscore due to a higher average score per question (0.79), making it the highest contributor to the total score of the SCARED.

The average total of the parent-reported SCARED was 28.49 (SD \pm 13.85 ; range 5 - 60) (Table 2). A total of 55 participants had a significant total score with greater than or equal to 25 , as per suggested by Birmaher et al. (54). The highest average total score on the subscales was for $\operatorname{GAD}(8.63, S D \pm 0.22)$, followed by Social Anxiety Disorder (7.13, SD \pm 0.29$)$ and Panic Disorder (5.54, SD \pm 0.26$)$. GAD was the highest subscore due to a higher average score per question (0.96), and also had the highest participants with a significant score in the 
subscore (51); this subscale may be a notable contributor to symptoms when compared to other subscales.

Table 2: Instrument Total Scores

\begin{tabular}{|c|c|c|c|c|}
\hline Instrument & $\begin{array}{l}\text { Subscale (\# of } \\
\text { Questions) }\end{array}$ & $\begin{array}{l}\text { Total Score } \\
\text { SD }\end{array}$ & $\begin{array}{l}\text { Average } \\
\text { score/question }\end{array}$ & $\begin{array}{l}\text { Significant } \\
\text { score }(n)\end{array}$ \\
\hline \multirow[t]{6}{*}{ SRS } & Total Score (65) & $\begin{array}{l}110.48 \pm \\
29.19\end{array}$ & 1.70 & 74 \\
\hline & Social Awareness (8) & $13.14 \pm 3.75$ & 1.64 & 49 \\
\hline & Social Cognition (12) & $20.73 \pm 6.47$ & 1.73 & 73 \\
\hline & $\begin{array}{l}\text { Social } \\
\text { Communication (22) }\end{array}$ & $\begin{array}{l}37.28 \pm \\
10.94\end{array}$ & 1.69 & 79 \\
\hline & $\begin{array}{l}\text { Social Motivation } \\
(11)\end{array}$ & $16.78 \pm 5.81$ & 1.53 & 54 \\
\hline & $\begin{array}{l}\text { Autistic Mannerisms } \\
\text { (12) }\end{array}$ & $21.87 \pm 7.14$ & 1.82 & 93 \\
\hline \multirow[t]{5}{*}{$\begin{array}{l}\text { SCARED } \\
\text { (Child) }\end{array}$} & Total Score (41) & $\begin{array}{l}27.06 \pm \\
15.88\end{array}$ & 0.66 & 38 \\
\hline & Panic Disorder (13) & $6.47 \pm 5.71$ & 0.50 & 41 \\
\hline & $\begin{array}{l}\text { Separation Anxiety } \\
\text { (8) }\end{array}$ & $5.23 \pm 3.52$ & 0.65 & 54 \\
\hline & $\begin{array}{l}\text { Social Anxiety } \\
\text { Disorder (7) }\end{array}$ & $6.40 \pm 4.24$ & 0.91 & 31 \\
\hline & School Avoidance (4) & $2.38 \pm 2.07$ & 0.60 & 42 \\
\hline \multirow[t]{3}{*}{$\begin{array}{l}\text { SCARED } \\
\text { (Parent) }\end{array}$} & Total Score (41) & $\begin{array}{l}28.49 \pm \\
13.85\end{array}$ & 0.69 & 42 \\
\hline & Panic Disorder (13) & $5.54 \pm 5.14$ & 0.43 & 30 \\
\hline & $\begin{array}{l}\text { Generalized Anxiety } \\
\text { Disorder (9) }\end{array}$ & $8.63 \pm 4.57$ & 0.96 & 51 \\
\hline
\end{tabular}




\begin{tabular}{lllll}
\hline Instrument & $\begin{array}{l}\text { Subscale (\# of } \\
\text { Questions) }\end{array}$ & $\begin{array}{l}\text { Total Score } \\
\text { SD }\end{array}$ & $\begin{array}{l}\text { Average } \\
\text { score/question }\end{array}$ & $\begin{array}{l}\text { Significant } \\
\text { score (n) }\end{array}$ \\
\hline $\begin{array}{l}\text { Separation Anxiety } \\
(8)\end{array}$ & $4.72 \pm 3.60$ & 0.59 & 47 \\
& $\begin{array}{l}\text { Social Anxiety } \\
\text { Disorder (7) }\end{array}$ & $7.13 \pm 4.18$ & 1.02 & 41 \\
& & & 43 \\
\hline
\end{tabular}

Correlation between the parent- and child-reported of the SCARED and the SRS

A moderate, statistically significant correlation between the parentreported of the SCARED and a positive screening of the SRS $(r=0.399, p=<$ 0.001) was observed. A weak, non-significant correlation was found between the child-reported of the SCARED and a positive screening of the SRS $(r=0.105, p$ $=0.300)$. A moderate, statistically significant correlation was found between the parent- and child- reported of the SCARED $(r=0.447, p=<0.001)$.

\section{Predictive ability of the SCARED on positive screening of the SRS via LASSO regression}

The cross-validation of the LASSO of the child-reported SCARED $(N=89)$ produced lambda value with the lowest mean-squared error of 0.100 . This lambda value was used to help identify the tuning parameter $\lambda$ for the LASSO regression model, but a lambda that was most regularized within one standard error was not reported. The most regularized lambda value is used for this model to prevent overfitting of the model to the dataset. Figure 1 shows the cross- 
validation results of the child-reported SCARED. Each bar shown in Figure 1 is a lambda value and $95 \% \mathrm{Cl}$ for the mean-squared error used in each iteration of the LASSO model, with the dotted line signifying the lambda value that gives the minimum mean-squared error in the cross-validation model. The top axis of Figure 1 explains how many questions of the SCARED are left in the model at each lambda value. With no optimal lambda value found from the crossvalidation model, this suggests that the most regularized lambda value is the model nearest to a lambda value of 0 . This result suggests that there is no optimal lambda value for this data, which can be due to insufficient sample size and limited statistical power to detect an association. The LASSO regression analysis resulted in none of the questions in the child-reported SCARED having a significant predictive ability of a positive screening on the SRS. The five questions with the largest lambda values before being dropped from the model are shown in Table 3. 
Figure 1: Cross-validation of the child-reported SCARED

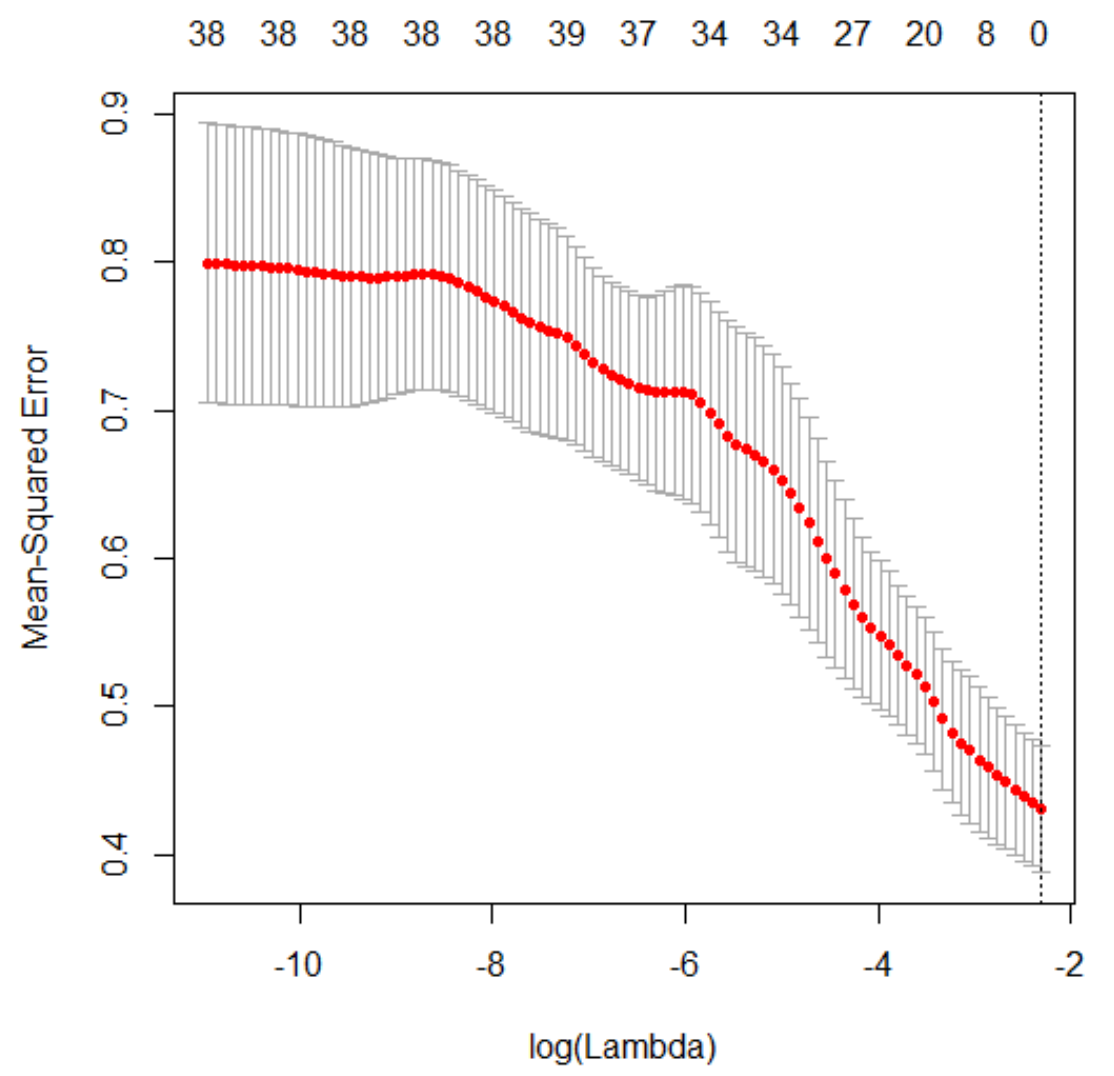

The cross-validation of the LASSO of the parent-reported SCARED $(N=$ 94) produced a lambda with the lowest mean-squared error of 0.062 , and found the most regularized lambda within one standard deviation of the minimum as 0.157. Figure 2 shows the cross-validation results of the parent-reported SCARED. Each bar shown in Figure 2 is a lambda value and 95\% confidence interval used in each iteration of the LASSO model. The left most dotted line signifies the lambda value that gives the minimum mean-squared error in the cross-validation model, while the right most dotted line signifies the lambda value that produces is the most regularized model that is within one standard error of the minimum error model. The top axis of Figure 2 explains how many questions 
of the SCARED are left in the model at each lambda value. The LASSO regression resulted in the ninth ("People tell me that my child looks nervous") and thirty-seventh ("My child worries about things that have already happened") question on the SCARED having a significant ability to predict a positive screening on the SRS. The five questions with the largest lambda values before being dropped from the model are shown in Table 3.

Figure 2 Cross-validation of the parent-reported SCARED

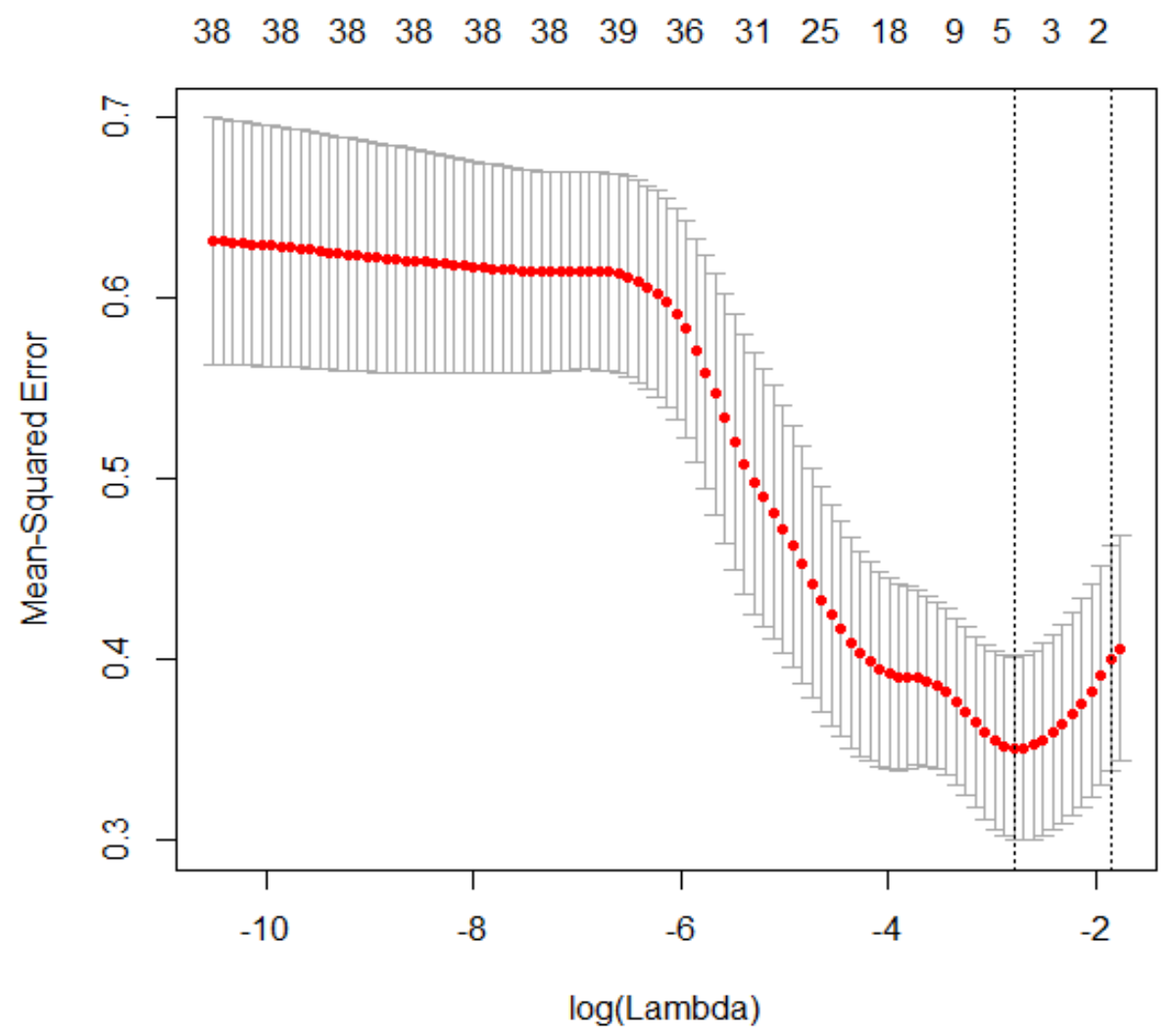


Table 3: Largest Lambda Values via the LASSO

\begin{tabular}{lll}
\hline SCARED instrument & Question \# & Lambda value \\
\hline Child & 1 & 0.088 \\
& 5 & 0.073 \\
& 6 & 0.100 \\
& 25 & 0.073 \\
Parent & 30 & 0.067 \\
& 1 & 0.115 \\
& $9^{*}$ & 0.172 \\
& 11 & 0.088 \\
& 19 & 0.074 \\
& $37^{*}$ & 0.159 \\
\hline
\end{tabular}

* Indicates significant predictability

Both question 9 ("Child looks nervous") and question 37 ("Child worries about things") were found to have a significant association with a positive screening of the SCARED when each question is put into the model individually and when each question is put into the same both logistic models (Table 4). Crude analysis shows that "Child looks nervous" of the parent-reported SCARED has a significantly higher odds of predicting a positive screening on the SRS, OR $=1.278(95 \% \mathrm{Cl}=1.144-1.429)$. Entered as a continuous variable, going from "not true" to "sometimes true" and "sometimes true" to "often true", there is a $27.8 \%$ increase in the odds that a patient will have a positive screening on the SRS. This is also when going the opposite way from "often true" to "sometimes true" to "not true. "Child worries about things" of the parent-reported SCARED also has a significant ability to predict a positive screening on the SRS, OR = $1.232(95 \% \mathrm{Cl}=1.113-1.364)$. Entered as a continuous variable, going from 
"not true" to "sometimes true" and "sometimes true" to "often true", there is a $23.2 \%$ increase in the odds that a patient will have a positive screening on the SRS. This is also when going the opposite way from "often true" to "sometimes true" to "not true.

Table 4: Assessment of Variables and Screening Positive on SRS

\begin{tabular}{lc}
\hline \multicolumn{1}{c}{ SCARED Question } & Crude OR (95\% Cl) \\
\hline “Child looks nervous" & $1.278(1.144-1.429)$ \\
"Child worries about things" & $1.232(1.113-1.364)$ \\
\hline
\end{tabular}

\section{Associations between the child- and parent-reported of the SCARED and SRS when stratified by demographics}

The relationship between "Child looks nervous" and "Child worries about things" from the parent-reported SCARED and a significant screening of the SRS was modeled including age, race, and sex. No collinearity was found in a model containing both "Child looks nervous" and "Child worries about things" (variance inflation factor $=1.175)$. No interaction term was found to be significant in the model (lowest p-value age*race: 0.334$)$, thus none were entered into the final model.

Models containing age, race, and sex were completed, resulting in crude $\mathrm{OR}=1.199(95 \% \mathrm{Cl}=1.067-1.347)$ for "Child looks nervous" and $\mathrm{OR}=1.190$ $(95 \% \mathrm{Cl}=1.070-1.324)$ for "Child worries about things". The model containing age and sex gave the most parsimonious model that fit closest to the crude model (age "Child looks nervous": $\mathrm{OR}=1.288$ [95\% Cl $=1.142-1.399]$, "Child 
worries about things": OR $=1.264$ [1.142 - 1.387], sex "Child looks nervous" OR $=1.199[1.069-1.345]$, "Child worries about things": OR $=1.186$ [1.067 1.317]), and was used for further analysis (Table 5).

\section{Table 5: Breakdown of Model Selection}

\begin{tabular}{lcc}
\hline \multicolumn{1}{c}{ Model } & $\begin{array}{c}\text { "Child looks nervous" } \\
\text { OR }(95 \% \mathrm{Cl})\end{array}$ & $\begin{array}{c}\text { “Child worries about things" } \\
\text { OR }(95 \% \mathrm{Cl})\end{array}$ \\
\hline Age/Race/Sex & $1.199(1.067-1.347)$ & $1.190(1.070-1.324)$ \\
Age/Race & $1.207(1.074-1.356)$ & $1.181(1.062-1.313)$ \\
Race/Sex & $1.196(1.137-1.429)$ & $1.165(1.046-1.297)$ \\
Age/Sex* & $1.199(1.069-1.345)$ & $1.186(1.067-1.317)$ \\
Age & $1.207(1.076-1.354)$ & $1.175(1.058-1.304)$ \\
Race & $1.201(1.066-1.352)$ & $1.161(1.043-1.292)$ \\
Sex & $1.197(1.064-1.347)$ & $1.160(1.043-1.291)$ \\
None & $1.202(1.069-1.351)$ & $1.156(1.040-1.285)$ \\
\hline
\end{tabular}

${ }^{*}$ Model used in analysis

Age was found to have a significant association between "Child looks nervous" and "Child worries about things" and a significant screening on the SRS $(\mathrm{OR}=1.141[95 \% \mathrm{Cl}=1.027-1.268])($ Table 6$)$. These results suggest that an increase in age group will have $14.1 \%$ higher odds to have a positive SRS screening from "Child looks nervous" and "Child worries about things" of the parent-reported SCARED compared to children in lower age groups. Sex was not found to be significant association between "Child looks nervous" and "Child worries about things" and a significant screening on the SRS (OR $=0.853[95 \%$ $\mathrm{Cl}=0.670-1.084])$. If significant, these results would suggest that females have 
a decrease of $14.7 \%$ odds of finding a positive screening on the SRS from "Child looks nervous" and "Child worries about things" of the parent-reported SCARED.

Table 6: Most Parsimonious Model for Assessment of Demographics

\begin{tabular}{ll}
\hline Model & OR (95\% Cl) \\
\hline "Child looks nervous" & $1.199(1.069-1.345)$ \\
"Child worries about things" & $1.186(1.067-1.317)$ \\
Sex & $0.853(0.670-1.084)$ \\
Age & $1.141(1.027-1.268){ }^{*}$ \\
\hline
\end{tabular}

${ }^{*}$ Indicates significance 


\section{DISCUSSION}

This is the first known report of comparing the SCARED and its ability to predict a positive screen for ASD using the SRS instrument, and illustrates crucial information on how anxiety and autism co-occur and how they are perceived by children and parents.

The parent-reported SCARED was significantly correlated with the childreported SCARED and significant score on the SRS; however a significant correlation between the child-reported SCARED and significant score on the SRS was not found. These results could be explained as parents interpreting externalized behaviors as anxiety, per suggested by Lohr et al. (55). The SRS was completed only by parents, and could result in a tendency to answer similar questions identically.

Logistic regression analysis via the LASSO showed there was no significant association between the child-reported version of the SCARED and a positive screening of ASD using the SRS instrument. There was a significant association between question nine and question thirty-seven of the parentreported version of the SCARED to a positive screening of the SRS. 
Sex and age were tested to have significant predictability of the association between these SCARED questions and a positive screening of ASD using the SRS instrument. Logistic regression models showed age as being a predictor of this association, meaning older children are more likely to have a positive screening on the SRS from question nine and thirty-seven of the parentreported SCARED. Previous studies report age as a significant risk factor on the co-occurrence of autism and anxiety $(25,26)$. This relationship could be explained by delayed development of cognitive and motor functions and the ability to express anxiety symptoms until later ages, as suggested by Davis et al. (26). Another possible explanation to this relationship is to the effects of public school and increasing anxiety symptoms in children with ASD compared to children with ASD who are home schooled due to the severity of the disorder.

Sex was not found to significantly predict the association between these SCARED questions and a positive screening of the SRS. This result contradicts previous studies looking at anxiety in children with ASD $(29,30)$, while supporting the results of other studies $(28,30,31)$. This could possibly be explained by shared neurobiological dysfunctions in both boys and girls with ASD having an overriding effect on psychopathology, resulting in the effects of anxiety levels being similar in boys and girls, as suggested by Brereton et al. (84). The small sample size of twelve females in the population could lead to an inability to detect a significant difference in the analysis.

Previous studies found as high as $84 \%$ co-occurrence of ASD and anxiety disorders in children, similar to the $87 \%$ of co-occurrence found in this study (1). 
Higher correlations were found in the parent-reported SCARED to positive screenings of autism from the SRS compared to findings from the child-reported SCARED to positive screenings of autism, showing similar conclusions gathered from other studies $(53,56,57)$. Similar significant predictability of co-occurrence in anxiety and ASD was found in studies using a different instrument $(30,41,47)$, as well as studies using the SCARED (53).

This study was conducted using data using non-stringent clinical diagnostic procedures, limiting its replicability. Clinical diagnoses were mostly conducted under the guidelines of the DSM-IV, but has been noted as to still diagnose social communications, allowing for the SCARED to yield clinically useful information (53). This population comes from a local psychiatry clinics, thus limiting the generalizability to the community at large.

\section{Strengths and Limitations}

There are several strengths to this study. This study is the first of its kind to look at the predicative abilities of both the parent-reported and child-reported versions of the SCARED for a significant score on the SRS. Each of these are validated and standardized measures, with each shown to be a valid measure in children with both anxiety and autism. The primary author of Lohr et al. (53) reviewed all diagnoses, along with review of school records prior to participation in the study. While there is no gold standard for co-diagnosis of these disorders, this study gives more information into how a correct co-diagnosis can occur, allowing for more precise treatments. All patients in the population are 
considered to have high-functioning autism, suggesting that patients are more likely to understand and properly answer questionnaires, limiting response bias.

This study is the first to utilize a novel method, LASSO regression, to predict the outcomes of one instrument from the scores on another instrument. Utilizing this once never used method gave a new look at the predictive abilities of instruments with a similar number of questions to number of participants. Using penalty regression methods, such as LASSO, can yield a wealth of new information, such as reliable predictability in populations of rare diseases with high levels of possible predictors, and should be used in future studies looking at predictive abilities of instruments.

This analysis has several limitations that require consideration. It was difficult to detect a significant predictive ability due to the small sample size. While no significant effects were found from the child-reported SCARED and only two found from the parent-reported SCARED, this analysis adds new and relevant data to the literature. Missing data limited the overall numbers that were used for the analysis.

Data for the child- and parent-reported SCARED were reported as continuous variables, causing possible cofounding of demographics to possibly be missed. The analysis of only two of the possible forty-one items of the parentreported SCARED could limit the overall predictability of the instrument, and exclude possible items that have a significant predictability of autism from the SRS instrument. 
Another limitation to address is the possibly of missing confounders by unmeasured measures (e.g., type of schooling, genetic factors, depression). The population only included $n=12$ females and non-White patients, limiting the ability to draw conclusions.

This population comes from local psychiatry clinics, thus limiting the generalizability to the community at large. Each clinical diagnosis was preexisting according to DSM-IV and DSM-5 criteria. A possible limitation from variability in diagnoses of across multiple clinics and physicians could lead to anchoring or confirmation bias. This could have an effect on the estimates as some patients in the population might be misclassified as having ASD or having an anxiety disorder. Most patients were diagnosed under the DSM-IV criteria, but has been noted as to still diagnose social communication, allowing for the SCARED to yield clinically useful information (53).

\section{Conclusion}

This study is the first to evaluate the predictive ability of the SCARED to the SRS, along with being the first study to examine the ability of the LASSO to identify the predictive abilities of one instrument to another. Although conducted with a small sample, two questions from the parent-reported SCARED were found to have a significant predictive ability of a significant score on the SRS. Future research using a larger sample and inclusion of possible confounders, such as genetic factors, schooling, and other co-occurring disorders will expand the knowledge between this association, allowing for a more precise estimation of co-occurring diagnosis, leading to better treatments for patients. Future studies 
may also look at the predictability of the SRS to a positive anxiety screening, and compare these results to determine if there are similar conclusions. 


\section{REFERENCES}

1. White SW, Oswald D, Ollendick T, Scahill L. Anxiety in children and adolescents with autism spectrum disorders. Clin Psychol Rev. 2009;29(3):21629.

2. American Psychiatric Association. (2000). Diagnostic and statistical manual of mental disorders (4th ed., rev.). Washington, DC. (Pg. 74).

3. Mazefsky CA, Kao J, Oswald DP. Preliminary evidence suggesting caution in the use of psychiatric self-report measures with adolescents with highfunctioning autism spectrum disorders. Res Autism Spectr Disord. 2011;5(1):16474.

4. Diagnostic and statistical manual of mental disorders. Arlington: American Psychiatric Publishing; 2013.

5. Christensen DL, Baio J, Braun KV, et al. Prevalence and Characteristics of Autism Spectrum Disorder Among Children Aged 8 Years - Autism and Developmental Disabilities Monitoring Network, 11 Sites, United States, 2012. MMWR Surveill Summ 2016;65(No. SS-3)(No. SS-3):1-23.

6. O'Hare W. The Changing Child Population of the United States: Analysis of Data from the 2010 Census 2011.

7. Merikangas K, He J, Burstein M, Swanson S, Avenevoli S, Cui L, et al. Lifetime Prevalence of Mental Disorders in US Adolescents: Results from the 
National Comorbidity Study-Adolescent Supplement (NCS-A). J Am Acad Child Adolesc Psychiatry. 2011;49:980-9.

8. Autism Spectrum Disorder: Signs and Symptoms Centers for Disease Control and Prevention 2017.

9. Huquet G, Ey E, Bourgeron T. The genetic landscapes of autism spectrum disorders. Annual Re Genomics of Human Genetics. 2013;14:191-213.

10. DiGuiseppi C, Hepburn S, Davis JM, Fidler DJ, Hartway S, Lee NR, et al. Screening for autism spectrum disorders in children with down syndrome: population prevalence and screening test characteristics. J Dev Behav Pediatr. 2010;31:181-91.

11. Cohen D, Pichard N, Tordjman S, Baumann C, Burglen L, Excoffier E, et al. Specific genetic disorders and autism: clinical contribution towards their identification. J Autism Dev Disord. 2005;25:103-16.

12. Hall SS, Lightbody AA, Reiss AL. Compulsive, self-injurious, and autistic behavior in children and adolescents with fragile X syndrome. Am J Ment Retard. 2008;113(1).

13. Zecavati N, Spence SJ. Neurometabolic disorders and dysfunction in autism spectrum disorders. Curr Neurol Neurosci Rep. 2009;9(2):129-36.

14. Durkin MS, Maenner MJ, Newschaffer CJ, Lee LC, Cunniff CM, Daniels $\mathrm{JL}$, et al. Advanced parental age and the risk of autism spectrum disorder. Am J Epidemiol. 2008;168(11):1268-76. 
15. Rosenberg RE, Law JK, Yenokyan G, McGready J, Kaufmann WE, Law PA. Characterisitics and concordance of autism spectrum disorders among 277 twin pairs. Arch Pediatr Adolesc Med. 2009;163(10):907-14.

16. Hallmayer J, Cleveland S, Torres A, Phillips J, Cohen B, Torigoe T, et al. Genetic heritability and shared environmental factors among twin pairs with autism. Arch Gen Psychiatry. 2011;68(11):1095-102.

17. Ronald A, Happe F, Bolton P, Butcher LM, Price TS, Wheelwright S, et al. Genetic heterogeneity between the three components of the autism spectrum: A twin study. J Am Acad Child Adolesc Psychiatry. 2006;45(6):691-9.

18. Taniai H, Nishiyama T, Miyahci T, Imaeda M, Sumi S. Genetic influences on the board spectrum of autism: Study of proband-ascertained twins. Am J Med Genet B Neuropsychiatr Genet. 2008;147B(6):844-9.

19. Ozonoff S, Young GS, Carter A, Messinger D, Yirmiya N, Zwaigenbaum L, et al. Recurrence risk for autism spectrum disorders: A Baby Siblings Research Consortium study. Pediatrics. 2011;128:488-95.

20. Sumi S, Taniai H, Miyahci T, Tanemura M. Sibling risk of pervasive developmental disorder estimated by means of an epidemiologic survey in Nagoya, Japan. J Hum Genet. 2006;51:518-22.

21. Christensen J, Gronborg TK, Sorensen MJ, Schendel D, Parner ET, Pedersen LH, et al. Prenatal valproate exposure and risk of autism spectrum disorders and childhood autism. JAMA. 2013;309(16):1696-703. 
22. Stromland K, Nordin V, Miller M, Akerstrom B, Gillberg C. Autism in thalidomide embryopathy: a population study. Dev Med Child Neurol. 1994;36(4):351-6.

23. Gardener H, Spiegelman D, Buka SL. Perinatal and neonatal risk factors for autism: a comprehensive meta-analysis. Pediatrics. 2011;128(2):344-55.

24. Becerra TA, von Ehrenstein OS, Heck JE, Olsen J, Arah OA, Jeste SS, et al. Autism spectrum disorders and race, ethnicity, and nativity: a populationbased study. Pediatrics. 2014;134(1):e63-71.

25. Davis TE, Hess JA, Moree BN, Fodstad JC, Dempsey T, Jenkins WS, et al. Anxiety symptoms across the lifespan in people diagnosed with autistic disorder. Research in Autism Spectrum Disorders. 2011;5:112-8.

26. Dickerson Mayes SD, Calhoun SL, Murray MJ, Zahid J. Variables Associated with Anxiety and Depression in Children with Autism. Journal of Developmental and Physcial Disabilities. 2011;23:325-37.

27. Vasa RA, Kalb L, Mazurek M, Kanne S, Freedman B, Keefer A, et al. Agerelated differences in the prevalence and correlates of anxiety in youth with autism spectrum disorders. Research in Autism Spectrum Disorders. 2013;7:1358-69.

28. Gadow KD, Devincent CJ, Pomeroy J, Azizian A. Comparison of DSM-IV symptoms in elementary school-age children with PDD versus clinic and community samples. Autism. 2005;9:392-415. 
29. Dubin AH, Lieberman-Betz R, Michele Lease A. Investigation of Individual Factors Associated with Anxiety in Youth with Autism Spectrum Disorders. J Autism Dev Disord. 2015;45(9):2947-60.

30. Sukhodolsky DG, Scahill L, Gadow KD, Arnold LE, Aman MG, McDougle CJ, et al. Parent-rated anxiety symptoms in children with pervasive developmental disorders: frequency and association with core autism symptoms and cognitive functioning. J Abnorm Child Psychol. 2008;36(1):117-28.

31. Worley JA, Matson JL, Sipes M, Koziowski AM. Prevalence of autism spectrum disorders in toddlers receiving early intervention services. Research in Autism Spectrum Disorders. 2010;5:920-5.

32. Wijnhoven L, Creemers DHM, Vermulst AA, Granic I. Prevalence and Risk Factors of Anxiety in a Clinical Dutch Sample of Children with an Autism Spectrum Disorder. Front Psychiatry. 2018;9:50.

33. Higgins DJ, Bailey SR, Pearce JC. Factors associated with functioning style and coping strategies of families with a child with an autism spectrum disorder. Autism. 2005;9(2):125-37.

34. Rao PA, Beidel DC. The impact of children with high-functioning autism on parental stress, sibling adjustment, and family functioning. Behav Modif. 2009;33(4):437-51.

35. Bellini S. Social skill deficits and anxiety in high-functioning adolescents with autism spectrum disorders. Focus on Autism and Other Developmental Disabilities. 2004;19:78-86. 
36. Bauminger N, Kasari C. Loneliness and friendship in high-functioning children with autism. Child Dev. 2000;71(2):447-56.

37. Chamberlain B, Kasari C, Rotheram-Fuller E. Involvement or isolation? The social networks of children with autism in regular classrooms. J Autism Dev Disord. 2007;37(2):230-42.

38. Lounds J, Seltzer MM, Greenberg JS, Shattuck PT. Transition and change in adolescents and young adults with autism: longitudinal effects on maternal well-being. Am J Ment Retard. 2007;112(6):401-17.

39. Montes G, Halterman JS. Characteristics of school-age children with autism. J Dev Behav Pediatr. 2006;27(5):379-85.

40. Park S, Park MH, Kim HJ, Yoo HJ. Anxiety and depression symptoms in children with Asperger syndrome compared with attention-deficit/hyperactivity disorder and depressive disorder. Journal of Child and Family Studies. 2013;22:559-68.

41. van Steensel FJ, Bogels SM, Perrin S. Anxiety Disorders in children and adolescents with autistic spectrum disorders. Clin Child Fam Psychol Rev. 2011;14(3):302-17.

42. Duvekot J, van der Ende J, Verhulst FC, Greaves-Lord K. Examining bidirectional effects between the autism spectrum disorder (ASD) core symptom domains and anxiety in children with ASD. J Child Psychol Psychiatry. 2017. 43. Wood JJ, Gadow KD. Exploring the Nature and Function of Anxiety in Youth with Autism Spectrum Disorders. Clinical Psychology Science and Practice 2010;17:281-92. 
44. de Bruin El, Ferdinand RF, Meester S, de Nijs PF, Verheij F. High rates of psychiatric comorbidity in PDD-NOS. Journal of Autism and Developmental Disorders. 2006;37:877-86.

45. Simonoff E, Pickles A, Charman T, Chandler S, Loucas T, Baird G. Psychiatric disorders in children with autism spectrum disorders: prevalence, comorbidity, and associated factors in a population-derived sample. . Journal of the American Academy of Child and Adolescent Psychiatry. 2008(47):921-9. 46. Joshi G, Petty C, Wozniak J, Henin A, Fried R, Galdo M, et al. The heavy burden of psychiatric comorbidity in youth with autism spectrum disorders: a large comparative study of a psychiatrically referred population. J Autism Dev Disord. 2010;40(11):1361-70.

47. Kaat AJ, Lecavalier L. Reliability and validity of parent- and child-rated anxiety measures in autism spectrum disorder. J Autism Dev Disord. 2015;45(10):3219-31.

48. Gotham K, Risi S, Pickles A, Lord C. The Autism Diagnostic Observation Schedule: Revised algorithms for improved diagnostic validity. . Journal of Autism and Developmental Disorders. 2007;37:613-27.

49. Sattler JM. Assessment of Children: Cognitive foundations. 5 ed. La Mesa, CA: Jerome M. Sattler Publisher Inc.; 2008.

50. Chorpita BF, Yim LM, Moffitt CE, Umemoto LA, Francis SE. Assessment of symptoms of DSM-IV anxiety and depression in children: A revised child anxiety and depression scale. Behaviour Research and Therapy. 2000;38:83555. 
51. March JS. Multidimensional Anxiety Scale for children. 2 ed. North Tonawanda, NY: Multi-Heath Systems; 2012.

52. Spain D, Sin J, Linder KB, McMahon J, Happe F. Social anxiety in autism spectrum disorder: A systematic review. Research in Autism Spectrum Disorders. 2018;52:51-68.

53. Lohr WD, Daniels K, Wiemken T, Williams PG, Kelley RR, Kuravackel G, et al. The Screen for Child Anxiety- Related Emotional Disorders is Sensitice but not Specific in Identifying Anxiety in Children with High-Functioning Autism Spectrum Disorder: A Pilot Comparison to the Achenbach System of Empirically Based Assessment Scales. Frontiers in Psychiatry 2017;8:1-10.

54. Birmaher B, Brent DA, Chiappetta L, Bridge J, Monga S, Baugher M. Psychometric properties of the Screen for Child Anxiety Related Emotional Disorders (SCARED): a replication study. J Am Acad Child Adolesc Psychiatry. 1999;38(10):1230-6.

55. Monga S, Birmaher B, Chiappetta L, Brent D, Kaufman J, Bridge J, et al. Screen for Child Anxiety-Related Emotional Disorders (SCARED): convergent and divergent validity. Depress Anxiety. 2000;12(2):85-91 .

56. Stern JA, Gadgil MS, Blakeley-Smith A, Reaven JA, Hepburn SL. Psychometric Properties of the SCARED in Youth with Autism Spectrum Disorder. Res Autism Spectr Disord. 2014;8(9):1225-34.

57. Wigham S, McConachie H. Systematic review of the properties of tools used to measure outcomes in anxiety intervention studies for children with autism spectrum disorders. PLoS One. 2014;9(1):e85268. 
58. Birmaher B, Khetarpal S, Brent D, Cully M, Balach L, Kaufman J, et al. The Screen for Child Anxiety Related Emotional Disorders (SCARED): Scale Construction and Psychometric Characteristics. Journal of the American Academy of Child and Adolescent Psychiatry. 1997;36:545-53.

59. Desousa DA, Salum GA, Isolan LR, Manfro GG. Sensitivity and specificity of the Screen for Child Anxiety Related Emotional Disorders (SCARED): a community-based study. Child Psychiatry Hum Dev. 2013;44(3):391-9.

60. Reaven J, Blakeley-Smith A, Culhane-Shelburne K, Hepburn S. Group cognitive behavior therapy for children with high-functioning autism spectrum disorders and anxiety: a randomized trial. J Child Psychol Psychiatry. 2012;53(4):410-9.

61. Constantino JN, Gruber CP. Social Responsiveness Scale. Los Angeles: Western Psychological Services; 2005.

62. Duvekot J, van der Ende J, Verhulst FC, Greaves-Lord K. The Screening Accuracy of the Parent and Teacher-Reported Social Responsiveness Scale (SRS): Comparison with the 3Di and ADOS. J Autism Dev Disord. 2015;45(6):1658-72.

63. Dunn G, Pickles A, Tansella M, Vazquez-Barquero JL. Two-phase epidemiological surveys in psychiatric research. Br J Psychiatry. 1999;174:95100.

64. Cholemkery H, Kitzerow J, Rohrmann S, Freitag CM. Validity of the social responsiveness scale to differentiate between autism spectrum disorders and disruptive behaviour disorders. Eur Child Adolesc Psychiatry. 2014;23(2):81-93. 
65. Azad G, Reisinger E, Xie M, Mandell DS. Parent and Teacher Concordance on the Social Responsiveness Scale for Children with Autism. School Ment Health. 2016;8(3):368-76.

66. Aldridge FJ, Gibbs VM, Schmidhofer K, Williams M. Investigating the clinical usefulness of the Social Responsiveness Scale (SRS) in a tertiary level, autism spectrum disorder specific assessment clinic. J Autism Dev Disord. 2012;42(2):294-300.

67. American Psychiatric Association. (2000). Diagnostic and statistical manual of mental disorders, text revision (DSM-IV-TR). (4th ed.). Washington, DC: American Psychological Association.

68. Murray MJ, Mayes SD, Smith LA. Brief report: excellent agreement between two brief autism scales (Checklist for Autism Spectrum Disorder and Social Responsiveness Scale) completed independently by parents and the Autism Diagnostic Interview-Revised. J Autism Dev Disord. 2011;41(11):158690.

69. Rutter M, Le Coutuer A, Lord C. Autism diagnostic interview revised western psychological services edition manual. Los Angeles: Western Psychological Services; 2008.

70. Herrington JD, Maddox BB, Kerns CM, Rump K, Worley JA, Bush JC, et al. Amygdala Volume Differences in Autism Spectrum Disorder Are Related to Anxiety. J Autism Dev Disord. 2017;47(12):3682-91.

71. Whalen PJ, Phelps EA. The human amygdala. New York: Guilford Press; 2009. 
72. Blackmon K, Barr WB, Carlson C, Devinsky O, DuBois J, Pogash D, et al. Structural evidence for involvement of a left amygdala-orbitofrontal network in subclinical anxiety. Psychiatry Res. 2011;194(3):296-303.

73. McDougle CJ, Naylor ST, Cohen DJ, Aghajanian MD, Heninger GR, Price LH. Effects of tryptophan depletion in drug-free adults with autistic disorder. Archives of General Psychiatry. 1996;53:993-1000.

74. Gordon CT, State RC, Nelson JE, Hamburger SD, Rapoport JL. A doubleblind comparison of clomipramine, desopramine, and placebo in the treatment of autistic disorder. Archives of General Psychiatry. 1993;50:441-7.

75. Chugani DC, Muzik O, Behen M, Rothermel R, Janisse JJ, Lee J, et al. Developmental changes in brain serotonin synthesis capacity in autistic and nonautistic children. Ann Neurol. 1999;45(3):287-95.

76. Graeff FG. Serotonin and anxiety.

77. Frith $C D$, Frith U. Interacting minds--a biological basis. Science. 1999;286(5445):1692-5.

78. Kornbrot, DE. Point biserial correlation. In: Everitt, BS.; Howell, DC., editors. Encyclopedia of Statistics in Behavioral Science. New York: Wiley; 2005. 79. Benesty J, Chen J, Huang Y, Cohen I. Pearson Correlation Coefficient. In: Noise Reduction in Speech Processing: Springer, Berlin, Heidelberg; 2009. 80. Ratner B. The correlation coefficient: Its values range between $+1 /-1$, or do they? Journal of Targeting, Measurement and Analysis for Marketing. $2009 ; 17(2): 139-42$. 
81. Tibshirani R. Regression Shrinkage and Selection via the Lasso. Journal of the Royal Statistical Society. 1996;58:267-88.

82. Pavlou M, Ambler G, Seaman SR, Guttmann O, Elliott P, King M, et al. How to develop a more accurate risk prediction model when there are few events. Research Methods \& Reporting. 2015;351.

83. Krstajic D, Buturovic LJ, Leahy DE, Thomas S. Cross-validation pitfalls when selecting and assessing regression and classification models. Journal of Cheminformatics. 2014;6(10).

84. Brereton AV, Tonge BJ, Einfeld SL. Psychopathology in children and adolescents with autism compared to young people with intellectual disability. J Autism Dev Disord. 2006;36(7):863-70. 


\section{CURRICULUM VITAE}

Austin Zachary

University of Louisville

Department of Epidemiology and Population Health

485 E Gray St.

Louisville, KY 40202

Cell: (502) 418-2423

aczach01@louisville.edu

\section{Education}

Masters of Science, Epidemiology, Expected: November 2018

University of Louisville, Louisville, KY

Bachelors of Science, Biology

Bellarmine University, Louisville, KY

\section{Research Experience}

2018 Graduate Research Assistant, Department of Communications, University of Louisville.

Superfund Research Center

Superfund T-32 Trainee

2017- 2018 Volunteer Research Assistant, College of Education and Human Development, University of Louisville.

$2015 \quad$ Kentucky Biomedical Research Infrastructure Network (KBRIN) Undergraduate program - University of Louisville. 


\section{Publications}

1. Zachary A., 2014. AmbT-1157, Accession JZ718306; Reproductive gene in the male flower and pollen, mRNA sequence. Ragweed (Ambrosia trifida) male flower and pollen cDNA library clone BU-R-1157 (5'). The Ambrosia Project, J.M Lau and D.L. Robinson, Bellarmine University, Louisville, KY. NCBI Accession: http://www.ncbi.nlm.nih.gov/nucest/JZ718306.1

2. Zachary A., 2014. AmbT-1156, Accession JZ718305; similar to putative senescence-associated family protein. Ragweed (Ambrosia trifida) male flower and pollen cDNA library clone BU-R-1156 (5'). The Ambrosia Project, J.M. Lau and D.L. Robinson, Bellarmine University, Louisville, KY. NCBI Accession: http://www.ncbi.nlm.nih.gov/nucest/JZ718305.1

\section{Upcoming Conference Papers}

1. (April 2019) "Growing Together: Community Engagement and Student Involvement"

Joy L. Hart, University of Louisville; Lindsay K. Tompkins, University of Louisville; Jack Pfeiffer, University of Louisville; Lindsey Wood, University of Louisville;

Austin Zachary, University of Louisville; Shelby Carter, University of Louisville; Delana Gilkey, University of Louisville; Delvon Mattingly, University of Michigan; Angel Thornsbury, University of Louisville; Kandi L. Walker, University of Louisville

2. (April 2019) "Engaging Communities, Engaging Change: Rural Middle and High School Youth and Tobacco Products"

Lindsay K. Tompkins, University of Louisville; Clara G. Sears, Brown University; Alexander S. Lee, Joel S. Duhl, Inc.; Courteney Smith, Independent Scholar; Allison Siu, Auburn University; Jack Pfeiffer, University of Louisville; Lindsey Wood, University of Louisville; Austin Zachary, University of Louisville; Kandi L. Walker, University of Louisville; Joy L. Hart, University of Louisville

3. (April 2019) "Translating Research for Community Members: Learning Partnerships and Change Mechanisms"

Lindsay K. Tompkins, University of Louisville; Jack Pfeiffer, University of Louisville; Lindsey Wood, University of Louisville; Austin Zachary, University of Louisville; Kandi L. Walker, University of Louisville; Joy L. Hart, University of Louisville 
4. Hart JL, Heberle L, Walker KL, Tompkins LK, Wheeler J, Pfeiffer J, Wood L, Gilkey D, Zachary A, Bhatnagar A: UofL Superfund Research Center: Engaging and communicating across disciplinary, professional, and institutional boundaries. In Superfund Annual Meeting. Edited by. Sacramento, CA; 2018.

\section{Notable Presentations}

2015 KBRIN Presentation

2015 Kentucky Academy of Science (KAS) Annual Meeting 